\title{
Diseases of travel, with particular reference to tropical diseases
}

\author{
A. W. WOODRUFF, \\ M.D., Ph.D., F.R.C.P., F.R.C.P.E., D.T.M. \& H. \\ London School of Hygiene and Tropical Medicine, and \\ Hospital for Tropical Diseases, London
}

\begin{abstract}
Summary
The large amount of disease acquired by travellers demonstrates that at present travel is not safe. Study of this disease, however, indicates that travel could be made safe by the application of relatively simple precautions.

Groups of travellers particularly liable to develop illness include those on short-term business and holiday trips to the Tropics. Young persons undertaking low cost overland journeys are particularly at risk. Among the important protozoal diseases acquired by travellers are malaria, trypanosomiasis, leishmaniasis and amoebiasis and the recent recognition of Lassa fever requires noting in connection with the diagnosis of fevers among persons who have recently travelled from West Africa.

It is most important that travellers should receive information on precautions they should take in tropical regions and that doctors in temperate regions should ask patients if they have recently travelled and, if the answer is in the affirmative, tropically-acquired disease should be considered.
\end{abstract}

THE special value of this meeting is that it is helping to disseminate knowledge of how to make travel safe. There are simple precautions which, if carefully applied, would make a tremendous difference to the situation.

Among those who travel to Britain, approximately ten have died from malaria annually in recent years; the numbers of those who have had non-fatal, though often serious, attacks are approximately twenty times this figure annually. Each year, too, there are deaths or serious morbidity in Britain among travellers with kala-azar, amoebic dysentery, liver abscess, filariasis, schistosomiasis, salmonelloses and much less serious morbidity from enteritis, malabsorption and common helminthic infections.

Recent changes in the pattern of travel in relation to tropical disease

An important factor in relation to this tropically acquired disease is the enormous increase which there has latterly been in short term travel to the tropics. Thus in $1973,20.7$ million people passed through London Airport whereas in 1950 the figure was 0.523 million. Of the 20.7 million, approximately 1.5 million arrived in Britain from the true tropics and about another 2-3 millions from the Mediterranean region. These figures by themselves indicate that at least one in fifty of the population in these islands has been exposed to disease in the true tropics within the recent past and that an additional one in twenty-five has been exposed to disease in the Mediterranean and subtropical regions. The figures take no account of the large numbers who travel to and from the tropics from other airports, nor do they take account of those who travel by sea, so that the proportions who have been exposed to tropical and subtropical disease are considerably in excess of the $1 / 50$ and $1 / 25$ quoted here. Another 2 million made international journeys beginning and ending at? airports other than Heathrow, and 9 million passengers made journeys by sea beginning or terminating in British seaports. The breakdown of where the additional group of arrivals came from is not available, but among the 4.5 million of them a large proportion was certainly from the tropics. Thus, in connection with air travel alone, busy services are operated from Gatwick to West Africa and South America. At a conservative estimate, therefore. one in ten to fifteen persons in Britain at the moment has been exposed to disease in the tropics or sub-tropics within the incubation period of most of the infective disorders which may be acquired there. This proportion is very much higher than it was in the years before the last vir. Then the military and administrative personncl working in the colonies and in India numbered, together with their commercial counterparts, a mere handful compared with the hosts of travellers that now visit these tropical and sub-tropical countries for longer or shorter periods.

\section{Air travel and social changes}

The advent of air travel which has made these changes possible has brought many social changes in its wake. Short business trips and holidays in tropical regions are now practicable, whereas 
formerly they were quite impossible. Not only have the number of those coming to Britain from the tropics greatly increased in recent years, but the shorter time which they spend on their air journey as compared with the longer sea passage has resulted in diseases with short incubation periods being seen in Britain, whereas formerly those affected would have developed their disease while on their sea journey and either have been put ashore en route or else have recovered by the time they docked in Britain. As a result of this we, at the Hospital for Tropical Diseases, London, have had patients with sandfly fever, psittacosis, salmonelloses and bacillary dysentery.

The development of the overseas holiday and/or business trip in far distant places goes on apace. Package tours to game parks in Africa are now common but very few of those going know anything of the medical risk involved and, unfortunately, the travel agents do little to overcome the lack of knowledge. Even among the well educated, serious avoidable disease is not uncommonly contracted. In the Daily Mail on 5th April, 1973, there was a report by one of their correspondents, Perrot Phillips, who had taken a package tour to Mombassa and had nearly died as a result. He had contracted malaria about which he had not been warned by the agents, and a spokesman for the travel agents' association was quoted as having stated that if the risks to health were emphasized they would not be able to sell their package tours to those parts. They regarded it as their business only to inform travellers of the legally required vaccinations. Indeed, in the available brochures much of the medical information is grossly misleading.

Holidays in the Mediterranean region involve less risk but nevertheless a considerable one. Thus, from the places to which this organization was arranging package tours, we in London have had patients with typhoid and Salmonella infection, amoebic dysentery, kala-azar and many helminthic infections. Indeed, the prevalence of kala-azar in some of the Mediterranean islands and around the Mediterranean generally is often underestimated. In the Medical Unit at the Hospital for Tropical Diseases there was admitted, for example, a child who had had a holiday of only 6 weeks' duration on one of the Greek islands, and who had never been to any other kala-azar endemic area but who we were able to prove had the infection.

Travellers on business. Those travelling on behalf of a large firm or organization are usually better informed concerning health risks than are holidaymakers. The medical staff of the organizations concerned will, in most cases, have considered what precautions should be taken by the members of their organization when going abroad. The Volunteer
Service Organization occupies a special place among these in that it comprises so many young people mosi of whom spend a year in out-of-the-way places 5 . teaching or doing social work of some kind. The opportunities for contracting infective disease under? these circumstances are considerable and, althoughe these personnel probably suffer less than holidaye travellers, they do bring a good deal of tropica尼 disease into Britain.

Overland journeys. Overland journeys, particularlyes to India and to parts of Africa, occupy a specia 5 place in the field of travel today. Most are done withminimal cost, the accommodation used is often of $\vec{w}$ the cheapest available as are the food and drink Conditions of hygiene on these trips are often verys poor indeed and the amount of ill health among the participants appears higher than in any other group- of the travelling public. For the last year or two thes Hospital for Tropical Diseases, London, has seldom been without a patient who had recently心 returned from one of these trips, and often has hado several such patients at a time. A high proportion? of them have had infectious hepatitis and after this, $\vec{\square}$ in order of frequency, have come the various dysen-D teries, helminthic infections and the malabsorption syndrome. A particular feature of this group is the to many of them have taken drugs; fairly prolonged? experience with cannabis is common among the्यnco and a considerable number have taken hard drug Indeed, it seems that for some, part of the attractions of the trip-the trip is a term which they may use both in the literal and metaphorical sense-is the opportunity to take these drugs and to obtain themo readily. In the summer, numbers hitch-hike to theo Mediterranean, more particularly to coastal regions of Spain and Portugal and, from questioninge patients, one learns that it is not unusual for some of this group not to trouble about arranging lod gings but, instead, merely to sleep on a beach at night. Among them there is not only the problem of? organic disease that they may contract but a very: considerable social problem.

Students. The number of enrolled students from overseas in Britain has over the past 5 years averaged 3 71,000 (British Council, Overseas Students in Britain, Statistical supplement, 1970-71). They? create a number of special medical problems particularly as so many of them are from the tropics. Regarding infective disease most, having lived for $N$ long periods in areas of high or moderate malarialn endemicity, have acquired a good deal of immunity to malaria and, in consequence, one seldom sees $\omega$ among them the severe forms of malaria that are encountered among travellers from this country to the tropics. Contrasting with travellers from this country, however, many of these students have been exposed for long periods to diseases of the ruralo 
tropics, and particularly may have come to this country with infections which have not greatly impaired their health before they left home but which may evolve slowly and cause severe illness after a long incubation period. Among the conditions in this category which have been encountered in the Medical Unit in London there have been trypanosomiasis, schistosomiasis, leprosy and tuberculosis. There is, therefore, among this group a particular need to be on the look-out for chronic disease. This disease may be relatively dormant and difficult to diagnose, and a further point of importance is that many of the difficult diagnostic problems presented by students will be encountered by practitioners in centres where little tropical disease is ordinarily seen. This arises because students become greatly dispersed, once they reach Britain, not only to the many universities but to technical and other colleges and, in the cases of nurses, often to quite small hospitals.

The psychological problems presented by these students from overseas are considerable. They are often under pressure from their families and from their governments to do well, for often their families are supporting them at considerable sacrifice, or else they have obtained a government grant. Psychosomatic or psychiatric trouble is a not infrequent result of the conflicts resulting from what is expected of the student and what they find themselves capable of doing. Thus, among a series of 150 patients, recently referred from the Hospital for Tropical Diseases for psychiatric opinion, there were 16 who were students.

Immigrants. Much of what has just been said about students applies equally to immigrants and this is particularly so regarding the frequency with which chronic disease is found among them. There is no need here to emphasize the extent of the problem caused by the numbers of immigrants; since the end of the last war it has been estimated that at least 1.9 million have come to Britain and that among these there are 0.75 million from Pakistan (Churches Committee, Geneva, 1968-69). One of the important social factors concerned with immigration is that the new arrivals are usually working men. Members of their families usually arrive later. This has led to considerable numbers of unattached males becoming concentrated in areas where work is available but where medical and social services may not be adapted for the influx.

\section{Health education regarding travel}

In setting the stage for the prevalence of tropical disease among travellers in Britain, health education concerning such disease and, still more important, the lack of education have important parts to play. The lack of this in so far as holiday travellers to the tropics are concerned has already been emphasized as has the almost irresponsible misguidance to which they may be subject. Although the situation is better for those belonging to organizations, information may still be acquired very casually, particularly if the traveller belongs to one of the smaller business concerns. Those who organize overland trips to India and elswhere, and those who go on them, commonly have very little knowledge of the diseases with which they may expect to come in contact and still less about how to avoid them. Those who return to Britain are, of course, given a card at the point of entry intended to warn practitioners whom they may consult of the possibility of certain acute infectious diseases such as smallpox. It is excellent as far as it goes, but big problems result from the often serious disease which is slower to develop among students and immigrants and to a lesser extent short-term travellers from the tropics. It is important to emphasize this hiatus in awareness and return to it in discussing, among the conclusions of this address, the action which is currently needed.

\section{Specific diseases of travellers Malaria}

Bearing in mind the serious illness and death which it causes, Plasmodium falciparum infection is un doubtedly the most important tropical disease encountered in Britain. Other forms of malaria are+ not uncommon but do not of course give rise to such severe illness.

Among those who develop severe $P$. falciparum infection, the pattern is remarkably constant. The traveller is almost invariably a person who was not born in a malarial area and has not lived in one for a long period of time. Following a visit to such an area, during which time he has not taken or has only irregularly taken a malarial prophylactic, he will have developed fever. In many cases, the patient will not have told his physician that he has been to the tropics and a diagnosis of influenza or gastrointestinal upset will be made and treatment given accordingly. Then, after 7 to 10 days of such treatment, the practitioner will be astonished on visiting the patient to find that he is delirious or perhaps comatose.

In patients of this kind the main dangers to life are the cerebral involvement which takes place and the renal failure. Prompt treatment with chloroquine is necessary and this drug is best given in half to one litre of normal saline by drip infusion. Dehydration is invariable in such patients, so that saline is necessary for this. Injection of the chloroquine directly intravenously is likely to be followed by shock, and the slower administration, possible by the means of intravenous drip, is much to be preferred. 
Details and management of severe and complicated malaria have been given by Woodruff (1971).

The severe shock-like mechanism which occurs in malaria of this kind leads to shut-down in renal blood flow with consequent tubular necrosis. If, however, the patient can be kept alive until the renal damage has had sufficient time to recover then, provided severe damage has not also been done to other vital organs, the outlook is good. Haemodialysis is ideal for this purpose but, if not available, peritoneal dialysis may be employed.

With a view to reducing cerebral oedema intravenous dexamethasone was introduced by Woodruff and Dickinson (1968) and its use has found wide acceptance.

In the prevention of malarial illness and death it cannot be stressed too strongly that personal prophylaxis against malaria should be employed by all travellers proceeding to tropical regions unless they have official information that all the countries to which they are proceeding are non-malarial. A question as to whether travel has recently been undertaken should be asked of all patients and if the patient has travelled to the tropics then the possibility of malaria and other tropical diseases will almost automatically be considered. In this and in many such infections diagnosis is not difficult once the condition has been thought of.

\section{Trypanosomiasis}

This should be suspected whenever a patient from Africa suffers from chronic febrile illness of which the cause is not known. Other features that raise suspicions include lymphadenopathy, headache, forgetfulness, impairment of cerebral function, skin rashes and epileptiform attacks. Among those with febrile illnesses in the tropics, malaria is usually over-diagnosed and trypanosomiasis under-diagnosed. In recent years, there have been a considerable number of cases of trypanosomiasis encountered in Europe among travellers from Africa and, regrettably, several of these have proved fatal.

\section{Leishmaniasis}

Visceral leishmaniasis is endemic in many parts of the Mediterranean littoral, and it should be suspected in patients who come from this area and who have persistent fever, anaemia, hepatosplenomegaly and/ or lymphadenopathy. This infection may have an incubation period of as long as 10 years so that when a patient develops it, it may be difficult to ascertain where it was acquired.

\section{Amoebiasis}

The two forms of amoebic infection most likely to be encountered among travellers are amoebic dysentery and amoebic liver abscess. The former is common though seldom life-threatening and should be suspected in all who, having travelled overseaso present with acute, sub-acute or chronic relapsing. diarrhoea.

Amoebic liver abscesses are often overlooked $\stackrel{\stackrel{5}{+}}{\frac{F}{0}}$ sometimes until they perforate into the peritoneunE or pleura and produce life-threatening disease $\overline{-}$ Symptoms which might lead one to suspect the presence of a liver abscess include, in addition to a history of travel, complaints of fever, an aching sensation in the right hypochondrium, malaise and $\bar{b}$ night sweats. In later stages when the diaphragm has become irritated by the abscess, pain may be referreof to the shoulder. A history of past amoebic dysentery is not invariable. Many infections of the liver, is seems, arise from silent or occult intestinal infections which develop as sequelae to an initial intestinal amoebic infection which is relatively transient or may? be asymptomatic. In such occult cases of amoebic liver abscess much help is obtained by hepaticu scintillography.

\section{Lassa fever}

This infection, first described from the village of Lassa in North East Nigeria in 1969 (Frame et al. $\stackrel{\mathbb{}}{\stackrel{乛}{8}}$ 1970) is one of the most dangerous currently known to man. The virus causing it has been placed in the group known as arenaviruses. They are probakye initially transmitted to man from rodents and the्तer from man to man in excreta, urine, vomit and bloo A high proportion of reported cases have occurreds among nursing attendants and others looking after patients who had acquired the disease. Infection, ing some cases fatal, has also occurred among laboratory西 workers carrying out research on the infection.

The symptoms include fever, lasting usually for about 3 weeks, an eruption on the throat leading to the development of small, whitish plaques on the mucosa, and prostration, much more severe than would be expected from the degree of fever present. Haemorrhagic features may develop.

The infection may present as a case of pyrexia of 3 undetermined origin in a person who has travelled from West Africa and a case of this kind has already 3 occurred in Britain (Woodruff et al., 1973). A specialo unit for the isolation of high risk patients has been developed at the Medical Unit, Hospital for Tropicalo Disease, London, where a small supply of convalescent serum from a patient who had had Lassa fevero is held.

\section{Conclusions}

Experience with these and other tropicallyacquired infections indicates that the only conclusion possible at the present time is that travel is not safe from the possibility of acquiring serious disease. It is important that all travellers proceeding 
overseas should be warned about the risks to which they become subject. If the travel agents will not do this then it would seem to be central governmental responsibility to make it obligatory to issue, with each ticket purchased for overseas travel, a leaflet giving in simple terms the precautions recommended against diseases such as malaria and enteric fever, concerning which there are no precautions which the traveller is legally required to take. It would also seem to be advisable to make it obligatory for travel brochures to give similar officially vetted information concerning the precautions travellers should take in the countries advertised.

Study of the diseases encountered among returning travellers reveals many social problems and among these is that which appears to be of growing proportions, namely those concerning travellers who go overseas by land sometimes, it seems, with the object of taking drugs. There appears to be an urgent need to set up study groups to look into this problem and to recommend the best way in which action can be taken to alleviate the resulting distress.

Concerning the diseases of immigrants there is need for active publicity in medical centres, and for postgraduate training regarding the medical problems which they may present. For these, and for all returning travellers, it is necessary to create an awareness of the nature of the diagnostic and therapeutic problems which have to be tackled among them. It is particularly important that doctors in small towns should be brought within the ambit of this programme directed towards increasing awareness of imported diseases.

In an address to the Medical Society of London (Woodruff 1958), the need to ask all patients about their geographic movements was emphasized and it was suggested that the question 'Have you travelled abroad recently?' should be asked every patient at the outset of the clinical interview. If this were done, suspicion of tropical disease would be greatly enhanced and such morbidity and mortality as it causes in Britain could be much reduced.

\section{References}

Frame, J.D., Baldwin, J.M., JNR., Gocke, D.J. \& Troup, J.M. (1970) Lassa fever, a new virus disease of man from West Africa. (i) Clinical description and pathological findings. American Journal of Tropical Medicine and Hygiene, 19, 670.

Woodruff, A.W. (1971) The treatment of severe and complicated malaria. Tropical Doctor, 1, 156.

Woodruff, A.W. \& Dickinson, C.J. (1968) The use of dexamethasone in cerebral malaria. British Medical Journal, 3, 31.

Woodruff, A.W., Monath, T.T., Mahmoud, A.A.F., Pain, A.K. \& Morris, C.A. (1973) Lassa fever in Britain; an imported case. British Medical Journal, 3, 616.

WoODRUFF, A.W. (1958) Tropical diseases in Great Britain Transactions of the Medical Society of London, 74, 140.

Churches Committee, Geneva (1968/9).

British Council, Overseas Students in Britain, Statisticat Supplement (1970/1). 